\title{
Neuer Vorstand der Palmengarten-Gesellschaft
}

Bei der Mitgliederversammlung 2007 hat die Palmengarten-Gesellschaft einen neuen Vorstand gewählt. Der bisherige Vorsitzende Prof. Dr. Georg Zizka schied nach 7-jähriger sehr erfolgreicher Tätigkeit aus beruflichen Gründen auf eigenen Wunsch aus. Während seiner Amtszeit stieg die Zahl der Mitglieder der Gesellschaft um $70 \%$, und der Umfang der Förderung des Palmengartens belief sich insgesamt auf stolze $400000 €$.

Der neue Vorstand besteht aus:

- Vorsitzender: Klaus URban

- Erste stellvertretende Vorsitzende und Schatzmeisterin: Herta MenK

- Zweiter stellvertretender Vorsitzender und

- Schriffführer: Herbert BiLLENSTeiner

Die beiden stellvertretenden Vorsitzenden sind seit Jahren im Vorstand tätig, Herta Menk seit 1997, Herbert Billensteiner seit 2000. Da Herta Menks Amtszeit ablief, war eine Neuwahl erforderlich. Sie stellte sich für ein weiteres Jahr zur Verfügung, um die Kontinuität im Vorstand zu gewährleisten und dem neuen Vorstand Zeit zu geben, die Nachfolge zu regeln. Sie wurde einstimmig wieder gewählt.

Neu in den Vorstand gewählt wurde KLAus URBAN, ehemaliger Personaldirektor einer internationalen Bank, seit zwei Jahren im Ruhestand. Klaus Urban ist, zusammen mit seiner Frau HeLGA, Übersetzer mehrerer englischer Rosenbücher und Autor verschiedener Gartenbücher (Themen: Kamelien und Rosen) und seit vielen Jahren ehrenamtlicher Mitarbeiter des Palmengartens. Bereits seit zwei Jahren ist er Mitglied des erweiterten Vorstands der Gesellschaft.

Der neue Vorstand will die bewährte Vielfalt des Angebots der Gesellschaft (Vorträge, Führungen, Studienreisen) weiterführen. Die Werbung neuer Mitglieder soll weiterhin im Vordergrund stehen. Derzeit hat die Gesellschaft über 1700 Mitglieder.

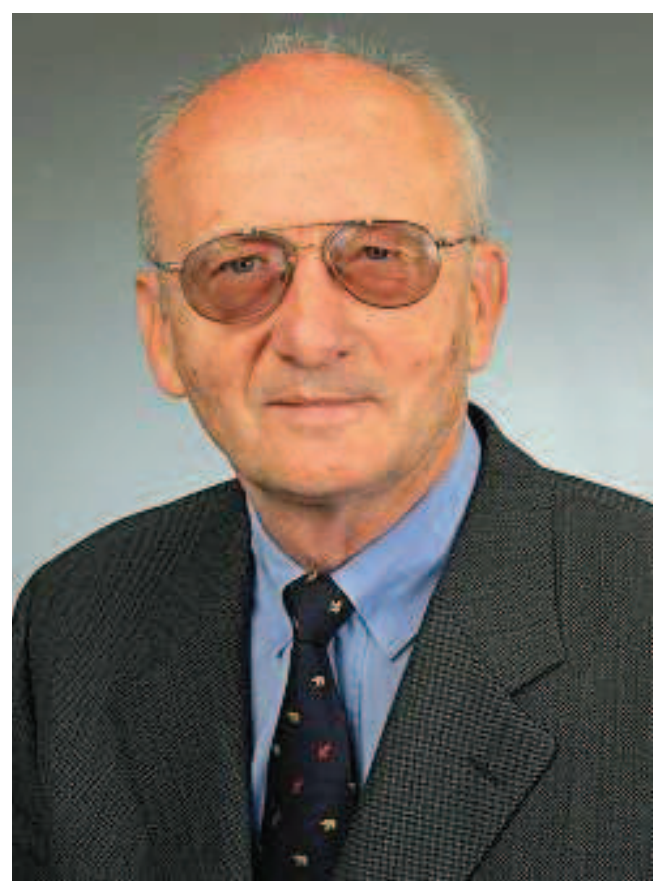

Die traditionsreiche, 1931 gegründete Gesellschaft hat satzungsgemäß den Auftrag, den Palmengarten zu fördern. So wurde 2006 aus Anlass des 75-jährigen Bestehens der Gesellschaft dem Palmengarten ein Scheck in Höhe von $75000 €$ als Anschubfinanzierung zur Erneuerung des Rosengartens überreicht (die Erneuerung ist gerade in vollem Gange). Neben zahlreichen Informations- und Weiterbildungsveranstaltungen zu gärtnerischen und botanischen Themen - die auch Nicht-Mitgliedern zugänglich sind - bietet die Gesellschaft ihren Mitgliedern ganzjährig freien Eintritt in den Palmengarten und zweimal jährlich kostenlos die Zeitschrift "Der Palmengarten«.

Informationen zur Gesellschaft in der Geschäftsstelle im Eingangsschauhaus des Palmengartens, Siesmayerstraße 63, 60323 Frankfurt, Tel. 0 69-745839; die Geschäftsstelle ist montags und donnerstags jeweils von 15.30 bis 17.00 Uhr geöffnet. Internetseite: www.palmengartengesellschaft.de. 